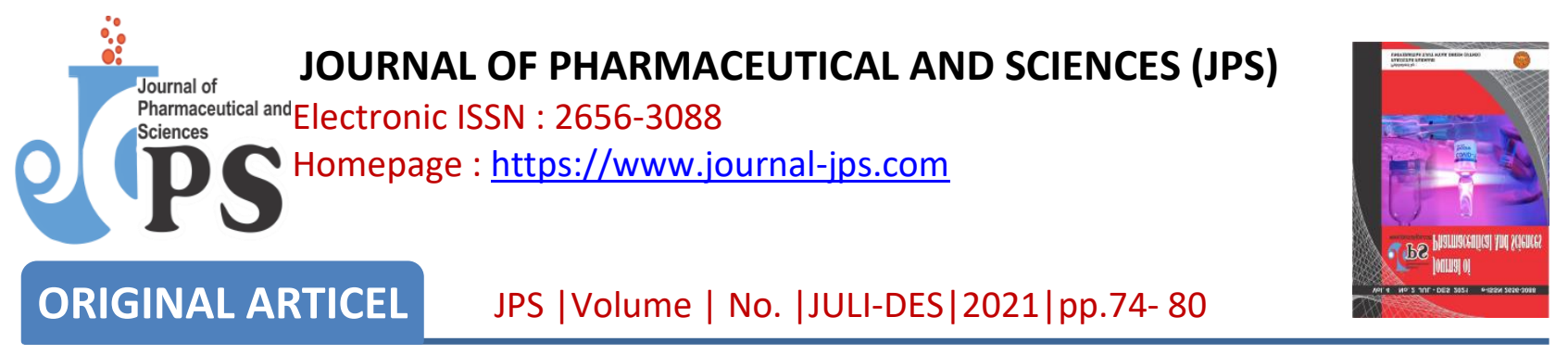

\title{
THE USE OF KESUMBA (Bixa orellana L.) FRUIT EXTRACT AS LIPSTICK COLORS
}

\author{
Meutia Indriana ${ }^{1}$, Salman $^{1}$ \\ ${ }^{1}$ Fakultas Farmasi, Universitas Tjut Nyak Dhien, Medan, Indonesia. \\ e-mail author : chinanaindria99@gmail.com
}

\begin{abstract}
Recently, there have been hundreds of lip color cosmetics on the market in various colors. However, not all lip colors are safe to use. Without realizing it, there are lip dyes that contain dyes that are dangerous and are prohibited because they can cause irritation to the skin and respiratory tract. Therefore, it is better to use natural dyes. One of the sources of natural dyes is the fruit of kesumba. Extracts from simplicia of kesumba seeds were made by percolation using $96 \%$ ethanol as a solvent. The lipstick formulation formula consists of Cera alba, vaseline alba, lanolin, carnauba wax, cetyl alcohol, oleum ricini, propylene glycol, titanium dioxide, butylhydroxytoluene, tween 80 , rose oil (oleum rosae), and nipagin, as well as the addition of kesumba seed extract with concentrations of $15 \%, 17.5 \%, 20 \%, 22.5 \%$, and $25 \%$. Tests on the preparations made included examination of the melting point, homogeneity, lipstick strength, stability test against changes in shape, color, and odor during 30 days of storage at room temperature, smear test, and $\mathrm{pH}$ examination, and irritation test preference test (Hedonic test). The results of the research that the extract of the kesumba fruit seed can be formulated in lipstick preparations with a light yellow to dark maroon color. The formulation of the kesumba seed extract in the lipstick preparation shows that the preparation is relatively stable homogeneous, the melting point is $58^{\circ} \mathrm{C}$, has a good lipstick strength, the $\mathrm{pH}$ ranges from 6.3 to 5.7 (according to the $\mathrm{pH}$ of the skin) easy to apply with an even color. , does not irritate, so it is safe to use; the pretty preferred preparations are preparations 2,3 , and 4 , namely the formula with extracts of kesumba seeds with concentrations of $17.5 \%, 20 \%$, and $22.5 \%$.
\end{abstract}

Keywords : Kesumba seeds, Bixa Orellana L., lipstick, lipstick components

\section{INTRODUCTION}

Cosmetics are used to beautify oneself formerly; they were mixed from natural ingredients found around them. Now cosmetics are made by humans from natural ingredients and synthetic materials to enhance beauty (Wasitaatmadja, 1997).

Lip color is a cosmetic preparation that is used to color the lips with an artistic touch to improve the aesthetics of makeup. Lip color preparations are available in various forms, such as liquids, crayons, and creams. Lip color in the form of liquid and cream will generally provide a membrane that is not durable and easily erased from the lips, so it is not very popular with people, especially when compared to lip color in the form of crayons. Crayon-shaped lip color is better known as lipstick (Anonymous,2008).

One of the Indonesian plants that can produce natural dyes is the seeds of the kesumba fruit (Bixa orellana L.), which contain anthocyanin dyes that can be used as natural dyes replace synthetic dyes (Anonymous, 2008).

Kesumba fruit is bright red, has a brushhaired surface, thin skin is slightly flat in shape, and has a hollow inside. Inside the cavity of the 
cassava fruit, there are about 50 tiny, bright red seeds. In the skin of the seeds of this fruit, there is a red pigment in a large enough volume. The dye of the seeds of the fruit of Kesumba is widely used in developed countries. It is usually used in the industry to color foods such as margarine, corned beef, sausages, cheese, drinks, plaiting materials, nail polishes, and lipstick (Anonymous ${ }^{b}, 2010$ ). Based on the description above, the researchers wanted to examine the seeds of the kesumba fruit, which was then continued in the formulation of lipstick preparations using natural dyes from the extract of the seeds of the kesumba fruit.

\section{MATERIALS AND METHODS}

The research method was experimental. The research included the preparation of samples of kesumba seeds (Bixa Orellana L.), the manufacture of extracts of the seeds of kesumba (Bixa Orellana L.), preparation of formulations, examination of the physical quality of the preparations and irritation tests of the preparations, as well as a preference test (Hedonic Test) on variations of the preparations made. Sampling was done purposively without comparing with other areas. The sample used in the experiment was fresh kesumba fruit seeds found in the yard of the residents of Kampung Madat, Simpang Ulim District, East Aceh. Plant determination was carried out at the Herbarium Medanense, Department of Biology, Faculty of Mathematics and Natural Sciences, USU. The collected samples were cleaned of other impurities, then peeled, and the seeds were taken.

\section{Preparation of Kesumba Fruit Seed Extract}

Simplicia powder was put into a closed vessel and macerated with $96 \%$ ethanol as a solvent, macerated for at least one night, protected from light while stirring frequently. The mass is transferred little by little into the percolator, then the filtered fluid is poured sufficiently, and on top of the simplicity, there is still a layer of the filtered fluid, the percolator is closed and left for 24 hours. The liquid is allowed to drip at a rate of $1 \mathrm{ml}$ per minute; the filtered fluid is added repeatedly so that there is always a layer of the solvent above the Simplicia until the liquid that comes out is no longer colorless, or the last liquid that comes out when vaporized does not leave a residue. The perchlorate was evaporated using a rotary evaporator at a temperature of $50^{\circ} \mathrm{C}$ to obtain a thick extract and then dried with a freeze dryer at a temperature of $-40^{\circ} \mathrm{C}$.

\section{Making Lipstick Using Kesumba Fruit Seed Extract as Colorant in Various Concentrations}

The basic formula is chosen for making lipstick in this study with the following composition (Young, 1974):

$\begin{array}{lll}\text { R/ } & \text { Cera alba } & 36.0 \\ & \text { Lanolin } & 8.0 \\ & \text { Vaseline alba } & 36.0 \\ \text { Cetyl alcohol } & 6.0 \\ \text { Oleum ricini } & 8.0 & \\ \text { Carnauba wax } & 5.0 & \\ \text { Coloring } & \text { taste } & \\ \text { Perfume } & & \text { taste } \\ \text { Preservative } & \text { taste } & \end{array}$

The formula was modified by adding components, namely propylene glycol, titanium dioxide, butylhydroxytoluene, and tween 80 . Kesumba fruit seed extract was insoluble in oleum ricini, so Propylene glycol was added to dissolve the dye. Propylene glycol used as a solvent is $5-80 \%$ (Rowe et al., 2009) in this study used as much as $8 \%$. Titanium dioxide as a pigment is used as much as $0.5 \%$. Butyl hydroxytoluene is used as an antioxidant of $0.0075-0.1 \%$ (Rowe et al., 2009). Based on hashes! Orientation towards using the colorant extract of the seeds of the fruit kesumba in the preparation of lipstick obtained results at a concentration of $12.5 \%$.

Table 1. Modification of the formulation of lipstick preparations using the colorant extract of the seeds of the kesumba fruit

\begin{tabular}{|l|c|c|c|c|c|c|}
\hline \multirow{2}{*}{ Composition } & \multicolumn{7}{|c|}{. } \\
\cline { 2 - 7 } & 1 & 2 & 3 & 4 & 5 & 6 \\
\hline Gera alba (gr) & 32.29 & 26.84 & 25.93 & 25.02 & 24.10 & 23.20 \\
\hline Lanolin (gr) & 7,17 & 5.96 & 5.76 & 5.56 & 5.36 & 5.15 \\
\hline Vaseline alba (gr) & 32.29 & 26.84 & 25.93 & 25.02 & 24.10 & 23.20 \\
\hline
\end{tabular}




\begin{tabular}{|l|c|c|c|c|c|c|}
\hline Cetyl alcohol (gr) & 5.38 & 4.47 & 4.32 & 4.17 & 4.02 & 3.87 \\
\hline Oleum ricini (gr) & 7.17 & 5.96 & 5.76 & 5.56 & 5.36 & 5.15 \\
\hline Carnauba wax (gr) & 4.48 & 3.73 & 3.60 & 3,47 & 3.35 & 3.22 \\
\hline $\begin{array}{l}\text { Kesumba seed } \\
\text { extract (gr) }\end{array}$ & 0 & 15 & 17.5 & 20 & 22.5 & 25 \\
\hline Propylene glycol (gr) & 8 & 8 & 8 & 8 & 8 & Titanium \\
\hline dioxide (gr) & 0.5 & 0.5 & 0.5 & 0.5 & 0.5 & 0.5 \\
\hline Oleum rosae (gr) & 0.1 & 0.1 & 0.1 & 0.1 & 0.1 & 0.1 \\
\hline BHT (gr) & 0.5 & 0.5 & 0.5 & 0.5 & 0,5 & 0.5 \\
\hline Nipagin (gr) & 0.1 & 0.1 & 0.1 & 0.1 & 0.1 & 0.1 \\
\hline Tween 80 (gr) & 2 & 2 & 2 & 2 & 2 & 2 \\
\hline
\end{tabular}

Description:

Preparation 1: Formula without extract of the seeds of the fruit of the seeds of the crimson fruit

Preparation 2: Formula with a concentration of $15.5 \%$ kesumba fruit seed extract

Preparation 3: Formula with a concentration of $17.5 \%$ of Kesumba seed extract

Preparation 4: Formula with a concentration of $20 \%$ of Kesumba seed extract

Preparation 5: Formula with a concentration of e Kesumba seed extract 22.5\%

Preparation 6: Formula with $25 \%$ concentration of

\section{Lipstick making procedure The}

Extract of the seeds of the Kesumba is dissolved in propylene glycol, added titanium dioxide which has been finely ground, after dissolved, butylhydroxytoluene and oleum ricini are stirred until homogeneous (mixture A). Weighed Cera alba, lanolin, vaseline alba, carnauba wax, and cetyl alcohol, put in a steamer cup, then melted on a water bath (mixture B). Then mixture $A$ was mixed into mixture $B$ slowly while stiring until homogeneous in a still-hot steamer cup, then added nipagin and tween after the temperature decreased, perfume was added. While it is thawing, put it in the mold and freeze it after freezing, the mass is removed from the mold and put in a container (roll-up lipstick).

\section{Examination of the physical quality of the preparation}

Physical quality examination of the preparation was carried out on each lipstick preparation. Physical quality inspection includes melting point inspection, homogeneity check, lipstick strength test, $\mathrm{pH}$ test, smear test, and stability of the preparation, which includes observing changes in shape, color, and odor of the preparation. After testing the physical stability of the preparation, then proceed with the irritation test and the hedonic test on the preparations made.

\section{RESULTS AND DISCUSSION}

Variations in the concentration of the colorant of the kesumba seed extract resulted in differences in the lipstick color. Lipstick with a concentration of $15 \%$ kesumba seed extract dye is bright yellow, $17.5 \%$ is dark yellow, $20 \%$ is yellowish red, $22.5 \%$ is bright maroon, and $25 \%$ is dark maroon. The scent of lipstick is the signature scent of oleum rosae.

Table 2. Data for examining melting point

\begin{tabular}{|c|c|}
\hline Preparations & Temperature $\left({ }^{\circ} \mathrm{C}\right)$ \\
\hline 1 & 58 \\
\hline 2 & 58 \\
\hline 3 & 58 \\
\hline 4 & 58 \\
\hline 5 & 58 \\
\hline 6 & 58 \\
\hline
\end{tabular}

Description:

Preparation 1: Formula without extract of the seeds of the coriander seeds. 
Preparation 2: Formula with a concentration of $15 \%$ of the fruit seed extract. Preparation 3: Formula with a concentration of $17.5 \%$ cassava seed extract Preparation 4: Formula with a $20 \%$ concentration of cassava seed extract Preparation 5: Formula with a concentration of $22.5 \%$ cassava seed extract Preparation 6: Formula with $25 \%$

The examination of the melting point of the lipstick showed that all lipstick preparations using kesumba seed extract dye melted at a temperature of $58^{\circ} \mathrm{C}$, indicating that the preparation made has a good melting point between $55-75^{\circ} \mathrm{C}$ (Directorate General of POM, 1985). Homogeneity examination showed that all lipstick preparations did not show any coarse grains when applied to transparent glass. All the preparations have a homogeneous composition (Directorate General of POM, 1979).
Examination of lipstick strength showed differences in the ability of lipstick preparations to withstand loads. This difference is caused by differences in the concentration of the kesumba seed extract used; the higher the concentration of the kesumba seed extract in the lipstick preparation, the less lipstick base is used. This causes lipstick with $25 \%$ kesumba seed extract to break more quickly than other lipstick preparations with a lower cassava seed extract concentration.

Table 3. Data on the strength of the lipstick

\begin{tabular}{|c|c|}
\hline. & Weight gain/gram \\
\hline 1 & 143.5 \\
\hline 2 & 103.5 \\
\hline 3 & 103.5 \\
\hline 4 & 103.5 \\
\hline 5 & 103.5 \\
\hline 6 & 93.5 \\
\hline 7 & 93.5 \\
\hline
\end{tabular}

The $\mathrm{pH}$ test results showed that preparation 1 was without seed extractKesumba fruit is 6.3 , while the preparations made using the extract of the seeds of Kesumba have a pH ranging from 5.7 to 6.2. Preparations without the extract of the seeds of the fruit have a higher $\mathrm{pH}$ than the preparations that use the extract of the seeds of the fruit because the higher the concentration of the extract of the seeds of the fruit, the lower the $\mathrm{pH}$ of the preparation.

Table 4. Data for measuring $\mathrm{pH}$ of

\begin{tabular}{|c|c|}
\hline preparations & $\mathrm{pH}$ \\
\hline 1 & 6.3 \\
\hline 2 & 6.2 \\
\hline 3 & 6.1 \\
\hline 4 & 6.1 \\
\hline 5 & 5.9 \\
\hline 6 & 5.7 \\
\hline
\end{tabular}

Table 5. Observing data on changes in shape, color, and odor of preparations

\begin{tabular}{|c|c|c|c|c|c|c|c|c|}
\hline \multirow{2}{*}{ Observation } & \multirow{8}{*}{ preparations } & \multicolumn{7}{|c|}{ Duration of observation ( day) } \\
\cline { 2 - 10 } & & 1 & 5 & 10 & 15 & 20 & 25 & 30 \\
\hline \multirow{3}{*}{ Form } & 1 & $\mathrm{~B}$ & $\mathrm{~b}$ & $\mathrm{~b}$ & $\mathrm{~b}$ & $\mathrm{~b}$ & $\mathrm{~b}$ & $\mathrm{~b}$ \\
\cline { 2 - 10 } & 2 & $\mathrm{~B}$ & $\mathrm{~b}$ & $\mathrm{~b}$ & $\mathrm{~b} \mathrm{~b}$ & $\mathrm{~b}$ & $\mathrm{~b}$ & $\mathrm{~b}$ \\
\cline { 2 - 10 } & 3 & $\mathrm{~B}$ & $\mathrm{~b}$ & $\mathrm{~b}$ & $\mathrm{~b} \mathrm{~b}$ & $\mathrm{~b}$ & $\mathrm{~b}$ & $\mathrm{~b}$ \\
\hline
\end{tabular}




\begin{tabular}{|c|c|c|c|c|c|c|c|c|}
\hline & 4 & $\mathrm{~B}$ & $\mathrm{~b}$ & $\mathrm{~b}$ & $\mathrm{~b} b$ & $\mathrm{~b}$ & $\mathrm{~b}$ & $\mathrm{~b}$ \\
\cline { 2 - 9 } & 5 & $\mathrm{~B}$ & $\mathrm{~b}$ & $\mathrm{~b}$ & $\mathrm{~b} \mathrm{~b}$ & $\mathrm{~b}$ & $\mathrm{~b}$ & $\mathrm{~b}$ \\
\hline & 6 & $\mathrm{~B}$ & $\mathrm{~b}$ & $\mathrm{~b}$ & $\mathrm{~b}$ & $\mathrm{~b}$ & $\mathrm{~b}$ & $\mathrm{~b}$ \\
\hline
\end{tabular}

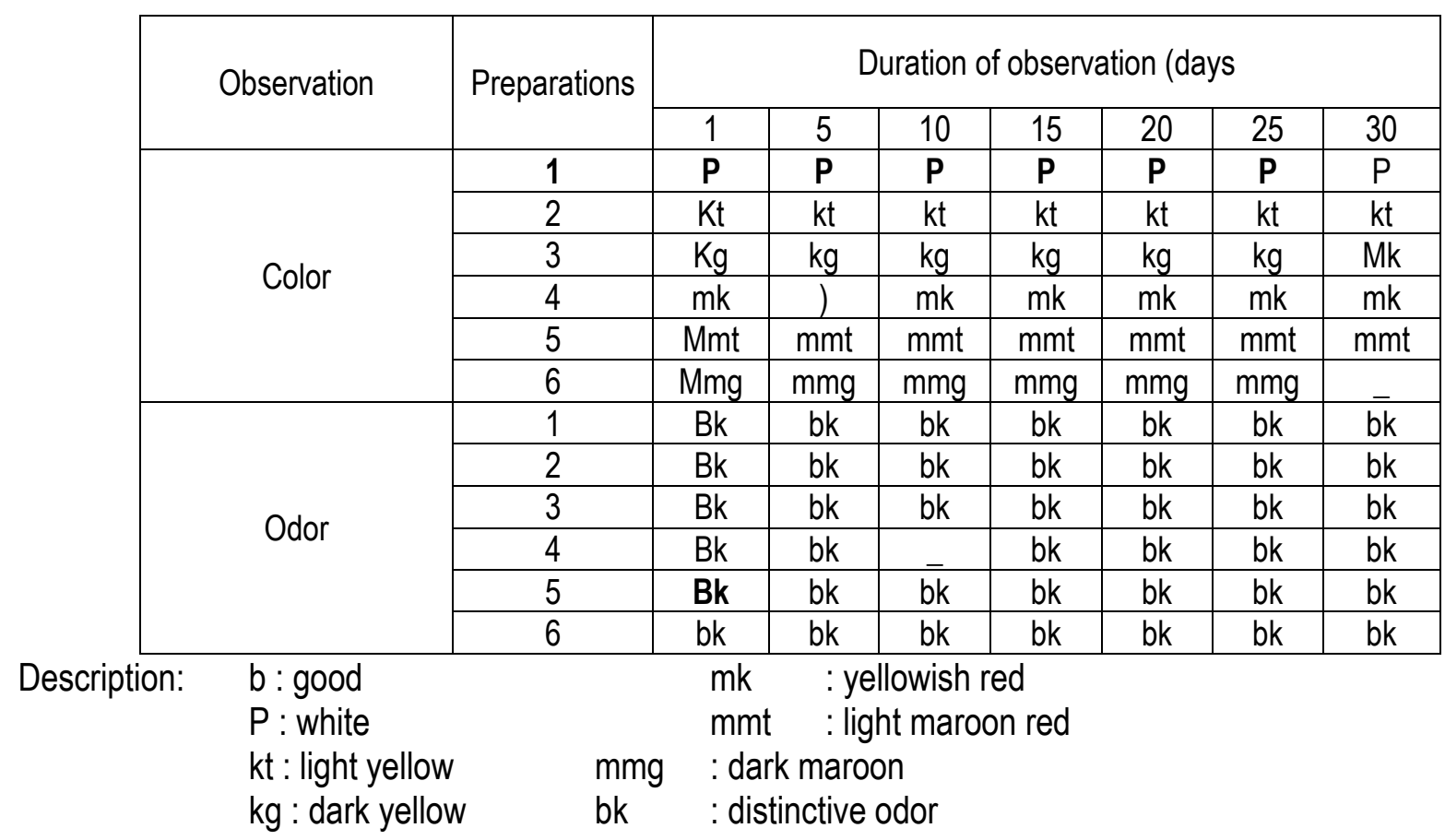

The results of the physical stability test for lip color preparations showed that all of the preparations had a good shape or consistency. The color produced is also quite good; the preparation with a concentration of $15 \%$ kesumba fruit seed extract gives a bright yellow color, $17.5 \%$ concentration of kesumba fruit seed extract gives a dark yellow color, $20 \%$ concentration of kesumba fruit seed extract gives a yellowish red color, the concentration of the seed extract Kesumba fruit $22.5 \%$ gives a bright maroon color, $25 \%$ concentration of kesumba fruit seed extract gives a dark maroon color. The odor produced by all preparations of each lip coloring formula is the distinctive smell of the perfume used, namely oleum rosae. A lipstick preparation is said to have good greasing power if it provides an intensive, even, and homogeneous color when applied to the skin on the back of the hand. Based on the smear test, it was found that the preparation that has excellent smearing power is preparation 5 , namely lipstick with a concentration of $25 \%$ kesumba seed extract. Hand Meanwhile, preparations 1 and 2 gave an intensive and even color after three applications because the color of the preparations was too light, so it can be concluded that preparations 1 and 2 had poor smearing power compared to preparations 5 . Preparations 3 and 4 were more accessible to apply than preparations 1 and 2.2 because the two times of application of the preparation have given an intensive and even color.

Table 6. Irritation test data

\begin{tabular}{|l|l|l|l|l|l|l|l|l|l|l|}
\hline \multirow{2}{*}{ observations } & \multicolumn{10}{|c|}{ Panelist } \\
\cline { 2 - 11 } & 1 & 2 & 3 & 4 & 5 & 6 & 7 & 8 & 9 & 10 \\
\hline
\end{tabular}




\begin{tabular}{|l|l|l|l|l|l|l|l|l|l|l|}
\hline Skin redness & $(-)$ & $(-)$ & $(-)$ & $(-)$ & $(-)$ & $(-)$ & $(-)$ & $(-)$ & $(-)$ & $(-)$ \\
\hline Itchy skin & $(-)$ & $(-)$ & $(-)$ & $(-)$ & $(-)$ & $(-)$ & $(-)$ & $(-)$ & $(-)$ & $(-)$ \\
\hline Swollen skin & $(-)$ & $(-)$ & $(-)$ & $(-)$ & $(-)$ & $(-)$ & $(-)$ & $(-)$ & $(-)$ & $(-)$ \\
\hline
\end{tabular}

Remarks : $\quad(-)$ : no irritation

$(+) \quad$ : skin redness

$(++) \quad$ : itchy skin

$(+++)$ : swollen skin

Test results irritation from the lip coloring formula with a concentration of $25 \%$ kesumba seed extract to 10 panelists by applying the preparation made to the skin of the inner forearm on all panelists for three consecutive days, indicating that all panelists gave negative results or not. Some signs indicate an irritation reaction to the preparations made. This shows that the preparation is relatively safe to use (Tranggono and Latifah, 2007).

Based on the hedonic test scores for 30 panelists, it was found that:

- Preparation 1 has a total score of 57

- Preparation 2 has a total score of 93

- Preparation 3 has a total value of 102

- Preparation 4 has a total score of 105

- Preparation 5 has a total score of 90

The data obtained from the assessment sheet (questionnaire) were tabulated, and the preference value

for each preparation was determined by finding the average result for each panelist at a 95\% confidence level.

From the calculation results, the preference value intervals for each preparation are:

- Preparation 1 has a preference value interval of $1.40-2.40$. The smallest value is taken for writing the final value of liking, namely 1.40 , and rounded up to 1 (Dislike).

- Preparation 2 has a preference value interval of 2.66-3.54. For writing the final favorite value, the smallest value is taken, which is 2.66 and is rounded up to 3 (quite like).

- Preparation 3 has a preference value interval of $3.0-3.80$. For writing the final value of liking, the smallest value is taken, which is 3.0 and is taken to be 3 (sufficiently like).

- Preparation 4 has a preference value interval of 3.11-3.89. The smallest value is taken for writing the final favorite value, namely 3.11 , and rounded up to 3 (Enough likes).

- Preparation 5 has a preference value interval of 2.46-3.54. The smallest value is taken for writing the final value of liking, namely 2.46, and rounded up to 2 (Less like).

From the results of the hedonic test on lipstick formulas with various concentrations for 30 panelists, it is known that the formulas that panelists prefer color are preparations 2,3 , and 4 , namely the formula with a concentration of $17.5 \%$, $20 \%$ kesumba seed extraction. And $22.5 \%$ with a total score of 93,102 , and 105 with a preference value of 3 . This is because lipsticks with concentrations of $17.5 \%, 20 \%, 22.5 \%$ are easy to apply and have given an even color, while the preparations that are not Preferred is preparation 1 , which is a formula with a concentration of $15 \%$ with a total value of 57 with a preference value of 1 , this is because the resulting color is too light and difficult to give color when applied. Preparation 5 is a formula with a concentration of $25 \%$ with a total value of 93 , with a preference value of 2 being less favorable. The lipstick is too old to be applied but easily gives color and is evenly distributed when applied.

\section{CONCLUSION}

Kesumba seed extract can be used as a colorant in the formulation of lipstick preparations. The colors that the panelists quite preferred were preparations 2, 3, and 4 with a concentration of $17.5 \%, 20 \%$, and $22.5 \%$ kesumba seed extract because they were easy to apply were intensive. Even color, with a total value of 93,102 , and 105. with their respective favorite values of 3 and the resulting colors are dark yellow, yellowish red, and bright maroon. While the preparations that the panelists favored were preparation 5 with a concentration of $25 \%$ and the resulting color was a dark maroon color, the preparations that the panelists did not like were preparation 1 with a concentration of $15 \%$, and the resulting color was 
a bright yellow color. The results of determining the physical quality of the preparations showed that all the preparations made were stable, did not show any changes in shape, color, and odor in storage for 30 days, had a homogeneous composition, $\mathrm{pH}$ ranging from 5.9-6.3, and had lipstick strength good one. Based on the results of the irritation test conducted on ten panelists, it showed that the lipstick preparations did not cause irritation and were relatively safe to use.

\section{REFERENCES}

Anonymousa. (2008). Lip balm. Retrieved 31 January, 2012.

http://zeiraf.blogspot.com/lip coloring.

Anonymous $^{b}$. (2010). Bixa Oreliana Linn or

Kesumba. Accessed 31 January, 2012.

http://ritarita.blogspot.com/bixa-orellana-

linn-kesumba.

Balsam, MS (1972). Cosmetic Science and Technology Second Edition. London. John Willy and Son, Inc. Case. 64, 209-371.

BPOM RI. (2003). Decree of the Head of the Food and Drug Supervisory Agency of the Republic of Indonesia Number.

KH.00.05.4.1745 About Cosmetics.

Retrieved 10 September 2012.

http://husinrm.files.wordpress.com./2008/0

2/kosmetik.pdf

BPOM RI. (2009). Public Warning / Warning

Number. KH.00.01.43.2503 11 June 2009.

Accessed September 15, 2012.

http://www.pom.go. id/ public/public

warning/default.asp

Directorate General of POM. (1979). Indonesian

Pharmacopoeia. Third Edition. Jakarta:

Indonesian Ministry of Health. Case. 7, 33.

Directorate General of POM. (1985). Indonesian

Cosmetics Formulary. Jakarta: Indonesian

Ministry of Health. Case. 83, 85,

195-197.

Directorate General of POM. (2000). General

Standard Parameters of Medicinal Plant

Extracts. Jakarta: Indonesian Ministry of Health. Hal: 7.

Hariana, HA (2007). Medicinal Plants and Their

Benefits Series 2. Jakarta: Self-help

Disseminator, p. 32-33.

Harborne, JB (1987). Phytochemical Method.

Determination of Modern Ways of

Analyzing Plants. Translated by Kosasih
Padmawinata. Bandung: ITB. Case. 7678.

Keithler. (1956). Formulation of Cosmetic and Cosmetic Specialties. New York: Drug and Cosmetic Industry. Case. 153-155.

Mitsui, Takeo. (1997). New Cosmetic Science. Amsterdam: Elsveir Science. Case. 3, 1921, 121, 386.

Poucher, WA (1979). Perfumes, cosmetics and soaps. 7th ed. London. Chapman an Hall. p.390

Rowe, CR, Paul JS, and Marian EQ (2009). Handbook of Pharmaceutical Excipients. Sixth Edition. Washington: Pharmaceutical Press. Case. 75, 378, 442, 592, 742.

Rawlins, EA (2003). Bentley's Text Book of Pharmaceutics. 18th Ed. London. Bailierre Tindall. Case. 355. Soekarto, ST, (1981). Organoleptic Assessment. Center for Food Technology Development. Bogor: IPB Press. Case. 45.

Tranggono, RI \& Latifah, F. (2007). Cosmetic Science Handbook. Jakarta: PT. Main Library Gramedia. Case. 3, 6-8, 11, 19-20, 90.

Vishwakarma, B., Dwivedi, S., Dubey, K., and Joshi, H. (2011). int. J. of Drug Discovery \& Herbal

Research. Ujjain Institute of Pharmaceutical Sciences, Ujjain. (MP) India. Case. 18-19.

Wasitaatmadja, SM (1997). Medical Cosmetic Science Guide. Jakarta: LA-Press. Case. 26, 28, 122, 124. Wibowo, DS (2005). Human Body Anatomy. Jakarta: Grasindo. Case. 165.

Winarto, WP (2007). Indonesian Medicinal Plants for Herbal Medicine Volume 1. Jakarta: Karyasari Herba Media. Case. 165-166.

Young, A. (1974). Practical Cosmetic Science. London: Mills \& Boon Limited. Case. 8. 